\title{
Structural and magnetic transformation of monodispersed iron oxide particles in a reducing atmosphere
}

\author{
L. C. Varanda and M. Jafelicci, Jr. \\ Instituto de Química de Araraquara, UNESP. CP 355-14801-970, Araraquara-SP, Brazil \\ P. Tartaj and K. O' Grady \\ Department of Physics, The University of York, Heslington, York, YO10 5DD United Kingdom \\ T. González-Carreño, M. P. Morales, ${ }^{\text {a) }}$ T. Muñoz, and C. J. Serna \\ Instituto de Ciencia de Materiales de Madrid, CSIC. Cantoblanco, 28049-Madrid, Spain
}

(Received 22 March 2002; accepted for publication 1 June 2002)

\begin{abstract}
Uniform metal iron ellipsoidal particles of around $200 \mathrm{~nm}$ in length were obtained by reduction and passivation of alumina-coated $\alpha-\mathrm{Fe}_{2} \mathrm{O}_{3}$ (hematite) particles under different conditions of temperature and hydrogen flow rate. The monodispersed hematite particles were prepared by the controlled hydrolysis of ferric sulfate and further coated with a homogeneous thin layer of $\mathrm{Al}_{2} \mathrm{O}_{3}$ by careful selection of the experimental conditions, mainly $p \mathrm{H}$ and aluminum salt concentration. The reduction mechanism of $\alpha-\mathrm{Fe}_{2} \mathrm{O}_{3}$ into $\alpha-\mathrm{Fe}$ was followed by x-ray and electron diffraction, and also by the measurements of the irreversible magnetic susceptibility. The transformation was found to be topotactic with the [001] direction of hematite particles, which lies along the long axis of the particles, becoming the [111] direction of magnetite and finally the [111] direction of metal iron. Temperature and hydrogen flow rate during the reduction have been found to be important parameters, which determine not only the degree of reduction but also the crystallite size of the final particles. Magnetic characterization of the samples shows that the only parameters affected by the crystallite size are the saturation magnetization and magnetic time-dependence effect, i.e., activation volume. (C) 2002 American Institute of Physics. [DOI: 10.1063/1.1496124]
\end{abstract}

\section{INTRODUCTION}

Advanced flexible media in the form of tapes or disks, used for the storage of digital and analog signals, consist almost exclusively of metal particles (MP). ${ }^{1-3}$ The main reason for using metals and alloys for recording applications rather than oxides is that they have higher values of saturation magnetization together with high-coercive field values. Their big drawback, however, is the need for protection against oxidation, which can be achieved by controlled oxidation of the particle's surface. ${ }^{4}$

The only commercially significant process for the production of iron metal particles (MP) is the reduction of acicular particles of oxyhydroxides. ${ }^{5,6}$ Silica or alumina are common elements added to the system to prevent sintering of the particles during the required heat treatment. ${ }^{7,8}$ The recording density achievable with these magnetic particles is limited by the coercivity and particularly the distribution of coercivities or switching fields within the material, which are closely associated with the crystallochemical characteristics of the particles (mainly, particle size distribution, coating homogeneity, and particle microstructure). ${ }^{2,9}$ Therefore, it seems necessary to undertake a detailed study of parameters such as heating temperature and reduction conditions to find out how these factors influence the structural and the magnetic characteristics of the final metal particles. Previous

a) Author to whom correspondence should be addressed; electronic mail: puerto@icmm.csic.es studies have mainly focused on the minimum temperatures required for the production of metal particles, ${ }^{10}$ however, to our knowledge, no study has been made of the effect of the reduction conditions (mainly hydrogen flow rate) on the structural and magnetic characteristics of the metal particles.

The aim of this work is to study the reduction mechanism to $\alpha-\mathrm{Fe}$ of alumina-coated microellipsoidal hematite particles, and to relate the crystallochemical characteristics of the obtained metal particles to their magnetic behavior. To reach this goal, monodispersed $\alpha-\mathrm{Fe}_{2} \mathrm{O}_{3}$ particles of $200 \mathrm{~nm}$ in length were prepared by the controlled hydrolysis of inorganic salts and then homogeneously coated with a thin layer of alumina. It is widely known that the controlled hydrolysis of inorganic salts can have significant advantages for the production of monodispersed fine particles with controlled microstructures, ${ }^{11}$ avoiding secondary effects from particle size or shape distributions. The use of these particles will, in addition, help to better understand the mechanisms that govern the formation of metal particles. Finally, the effect of some reduction parameters such as temperature and hydrogen flow on the crystallographic and magnetic characteristics of the final particles were investigated.

\section{EXPERIMENTAL SECTION}

\section{A. Sample preparation}

Reagent-grade ferric sulfate, $\mathrm{Fe}_{2}\left(\mathrm{SO}_{4}\right)_{3} .5 \mathrm{H}_{2} \mathrm{O}$ (Aldrich), aluminum nitrate, $\mathrm{Al}\left(\mathrm{NO}_{3}\right)_{3} \cdot 9 \mathrm{H}_{2} \mathrm{O}$ (Aldrich), sodium dihydrogen phosphate, $\mathrm{NaH}_{2} \mathrm{PO}_{4}$ (Fluka), sodium hydroxide, 


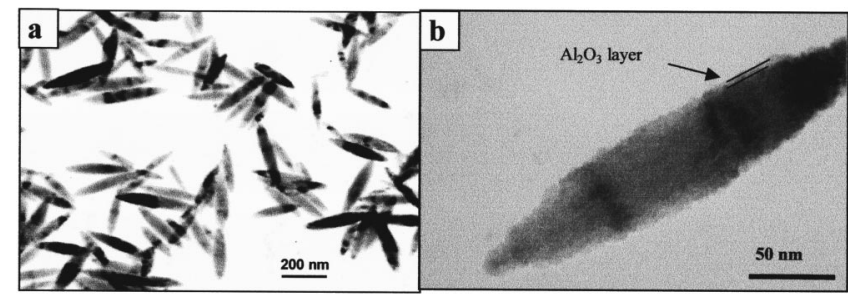

FIG. 1. Uniform hematite particles: (a) as prepared and (b) coated with an aluminum oxide layer.

$\mathrm{NaOH}$ (Aldrich), and hydrochloric acid, $\mathrm{HCl}$ (Panreac) were used without further purification and the solutions were prepared using doubly distilled water.

Monodispersed ellipsoidal hematite particles of 220 $\pm 20 \mathrm{~nm}$ in length with an axial ratio of $\sim 6$ were synthesized following a method described earlier ${ }^{12}$ (Fig. 1). $\mathrm{Fe}_{2}\left(\mathrm{SO}_{4}\right)_{3}$ (0.01 moles) was dissolved in $250 \mathrm{~mL}$ of water to which $1 \mathrm{M}$ $\mathrm{NaOH}$ solution was added under stirring to reach a $p \mathrm{H}$ of $\sim 10.5$. The resulting brown precipitate was washed with water and the supernatant liquid was decanted. The procedure was repeated several times until a $p \mathrm{H}$ of $\sim 9.3$ was reached. Then, $10 \mathrm{~mL}$ of a solution $1.0 \mathrm{M} \mathrm{HCl}$ and $4.0 \times 10^{-4} \mathrm{M}$ $\mathrm{NaH}_{2} \mathrm{PO}_{4}$ were added to $200 \mathrm{~mL}$ of the suspension and aged at $100 \pm 2{ }^{\circ} \mathrm{C}$ for $48 \mathrm{~h}$. The product from this hydrolysis was filtered, washed to eliminate impurities, and dried at $100^{\circ} \mathrm{C}$ for $24 \mathrm{~h}$.

To prevent interparticle sintering during the heating, the hematite particles were coated with aluminum oxide. ${ }^{13}$ The coating process involved first the dissolution of aluminum nitrate in $100 \mathrm{~mL}$ of water and then the addition of a $10 \%$ $\mathrm{NaOH}$ aqueous solution to reach a $p \mathrm{H}$ of 12.5 . Hematite particles $(1.0 \mathrm{~g})$ were homogeneously suspended in the solution and carbon dioxide gas was blown into the slurry to lower the $p \mathrm{H}$ to a value of 7.5. In this way, a hydrated aluminum oxide $\left(\mathrm{Al}_{2} \mathrm{O}_{3} \cdot \mathrm{nH}_{2} \mathrm{O}\right)$ layer was deposited onto the surface of the hematite particles. ${ }^{13}$ Finally, the coated particles were filtered, washed with water, dried, and dehydroxylated by heating at $400{ }^{\circ} \mathrm{C}$ for $3 \mathrm{~h}$. It was found that rigorous $p \mathrm{H}$ control was essential for the production of homogeneous alumina coatings. Thus, the initial $p \mathrm{H}$ was set to 12.5 because in this region, the surface of the hematite particles is negatively charged, and the suspension is stabilized by electrostatic forces. ${ }^{14}$ For the coating process, the $p \mathrm{H}$ was set to 7.5 because the isoelectric points of aluminum hydroxide and hematite are 9 and 6.5, respectively. ${ }^{14}$ Therefore, at $p \mathrm{H} 7.5$ the surface of the hematite particles remains negative, while the surface of the aluminum hydroxide nuclei is positively charged, favoring the heterocoagulation process and the formation of a homogenous coating. One could also start from an acidic $p \mathrm{H}$, instead of basic, in order to stabilize the hematite particles, but in this case, when increasing the $p \mathrm{H}$ to the optimum value to produce heterocoagulation (7.5), the hematite particles need to pass through their isoelectric point, which induces particle aggregation and nonhomogeneous coatings. Another parameter that affects the homogeneity of the alumina coating is the initial concentration of the $\mathrm{Al}\left(\mathrm{NO}_{3}\right)_{3}$, which was found to be optimum at $10^{-2} \mathrm{M}$. Higher concentrations drive to the segregation of aluminum

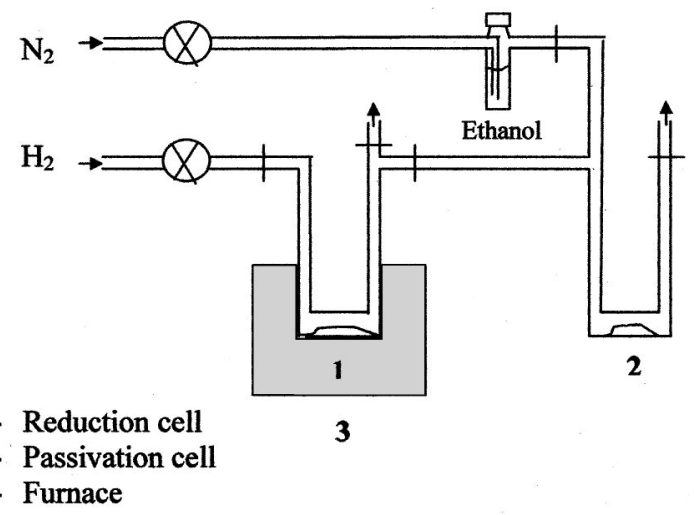

FIG. 2. Experimental setup for the reduction passivation of the samples.

hydroxide in the form of separate particles. Meanwhile, lower concentrations result in the partial coverage of the particles as detected by TEM.

Reduction of the samples was carried out in the experimental setup shown schematically in Fig. 2. To study the reduction process, the alumina-coated $\alpha-\mathrm{Fe}_{2} \mathrm{O}_{3}$ samples were heated at $450{ }^{\circ} \mathrm{C}$ under different flow rates of hydrogen (from 6 to $0.2 \mathrm{~L} / \mathrm{h}$ ). Aliquots were collected at different times from the reduction cell (1) and moved into the passivation cell (2) with a magnet, to follow phase evolution. The samples collected were cooled to room temperature under the hydrogen atmosphere. Finally, nitrogen gas was blown into a flask containing ethanol and the resulting stream was passed through the sample in order to slightly passivate the iron particle's surface. Without passivation samples (especially those containing the highest amount of $\alpha-\mathrm{Fe}$ ) rapidly oxidized upon exposure to air.

\section{B. Characterization techniques}

Phase evolution in the samples was followed by powder X-ray diffraction (XRD) using a Philips 1710 diffractometer and $\mathrm{Cu} \mathrm{K} \alpha$ radiation. The crystallite size of the hematite, magnetite, and metal iron particles was calculated from the full width at half maximum (FWHM) of the (104), (311), and (110) reflections, respectively, using the Scherrer equation. ${ }^{15}$ The morphology, particle size, and distribution were examined by transmission electron microscope (TEM, JEOL-2000 FXII). For TEM examination the powders were dispersed in toluene in an ultrasonic bath for one hour and then a drop of this solution was deposited onto a carbon-coated copper grid. In all cases, the average particle length and the standard deviation were calculated by counting around 100 particles. The same microscope was used for selective area diffraction (SAD) and high resolution imaging (HRTEM) studies on individual particles.

The magnetic characterization of the samples was carried out in a PAR 4500 Vibrating Sample Magnetometer. Coercivity $\left(H_{C}\right)$ and saturation magnetization $\left(M_{S}\right)$ values were obtained from the hysteresis loops at room temperature with a maximum applied field of $1 \mathrm{~T}$. The samples were prepared by packing the powder into a plastic tube such that the axial ratio of the resulting sample was greater than five. In this way, the need to correct for sample shape demagnetizing effects was avoided. 
The activation volume $V_{a}$ (i.e., volume of the magnetic material which reverses coherently) was obtained from timedependence measurements of the magnetization, following the method described in detail by de Witte et al. ${ }^{16}$ and analyzed using the method of Gaunt. ${ }^{17}$ The equation used to determine $V_{a}$ was

$$
V_{a}=k_{\mathrm{B}} T / H_{f} M_{s}
$$

where $k_{\mathrm{B}}$ is Boltzmann's constant, $T$ the temperature, and $H_{f}$ is the fluctuation field, which represents the effect of thermal energy on the magnetization of the sample $\left(H_{f}=S / \chi_{\text {irr }}\right)$. In this equation, $S$ is the coefficient of magnetic viscosity ( $S$ $=-d M / d[\ln (t)])$ and $\chi_{\text {irr }}$ is the irreversible susceptibility, which can be obtained from the differential of the demagnetizing remanence curve (DCD). DCD curves were obtained by measuring the remanent magnetization after removing a negative field applied to an initially saturated (in the positive direction) sample. In particular, the value of the irreversible susceptibility, $\chi_{\mathrm{irr}}(H)$ obtained from the differential of the DCD curve, has also been used to follow the transformation of $\mathrm{Fe}_{3} \mathrm{O}_{4}$ into $\alpha-\mathrm{Fe}$.

\section{RESULTS AND DISCUSSION}

\section{A. Transformation mechanism of $\alpha-\mathrm{Fe}_{2} \mathrm{O}_{3}$ into $\alpha-\mathrm{Fe}$}

The transformation mechanism of the hematite particles to $\alpha-\mathrm{Fe}$, at $450{ }^{\circ} \mathrm{C}$, was followed by collecting samples at different times during the reduction process (C2T series). For this series, a hydrogen gas flow rate of $2 \mathrm{~L} / \mathrm{h}$ was used. The XRD of the samples collected just after reaching $450^{\circ} \mathrm{C}$ under the hydrogen flow (labeled as time 0 ), showed only peaks due to magnetite (Fig. 3). At this point, electron diffraction and the corresponding high-resolution images of one particle resemble that of a single crystal with planes (111) oriented perpendicular to the long axis of the particles (Figs. 4 and 5). This result clearly indicates that the transformation from hematite to magnetite is topotactic. In particular, the direction [001] of hematite, which lies along the long axis of the particles, becomes the [111] planes of magnetite as observed in the high-resolution image presented in Fig. 5. The same [111] direction along the long axis was observed for magnetite particles obtained from hematite through a reductionoxidation process. ${ }^{18}$ However, when magnetite is obtained from goethite, the long particle dimension lies along the [110] direction. ${ }^{19}$ The crystallite size of the magnetite at this stage calculated from the (311) reflection was around $60 \mathrm{~nm}$, which is similar to the crystal size calculated for the hematite precursor from the (104) reflection. Both planes form a similar angle $\left(30^{\circ}\right)$ with the corresponding direction of the long particle dimension which seems to suggest that the monocrystaline character of the particles is preserved during the transformation from hematite to magnetite.

After 90 min reduction, a small peak of $\alpha$ iron can be observed in the XRD pattern, suggesting the onset of the transformation of magnetite to $\alpha$-iron (Fig. 3). The electrondiffraction patterns observed for several particles at this stage show single-crystal behavior (Fig. 4). However, the spots corresponding to the (004) and (440) planes become brighter. This effect is more pronounced for the sample reduced for

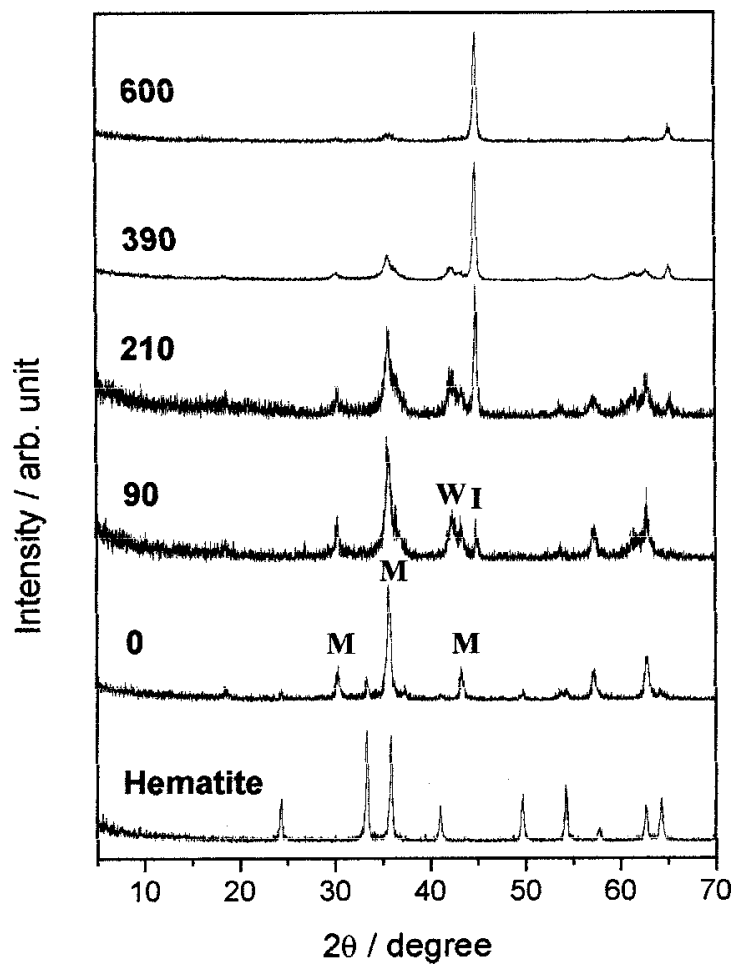

FIG. 3. X-ray diffraction patterns for sample $\mathrm{C} 2 \mathrm{~T}$ at different reduction times $(0,90,210,390$, and $600 \mathrm{~min}) . M, W, I$ indicate the most intense peaks of magnetite, wustite, and iron, respectively.

210 min (Fig. 4). These planes have the same interplanar spacing (2.07 and $1.48 \AA$, respectively), as the (110) and (002) planes of the $\alpha-\mathrm{Fe}$ structure (2.02 and $1.43 \AA$, respectively). Therefore, we conclude that the [001] and the [110] directions of magnetite become the [110] and the [001] directions of iron, respectively. Moreover, from these results, it can be inferred that the [111] direction of magnetite, which lies along the long axis of the particles, becomes the [111]

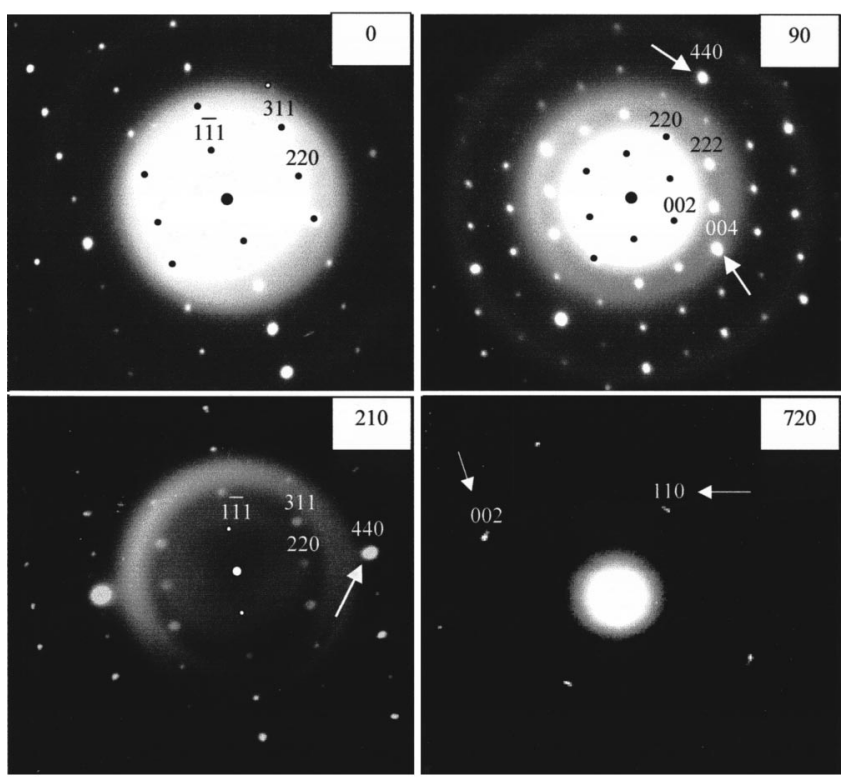

FIG. 4. Electron-diffraction patterns for sample C2T at different reduction times $(0,90,210$, and $720 \mathrm{~min})$. 


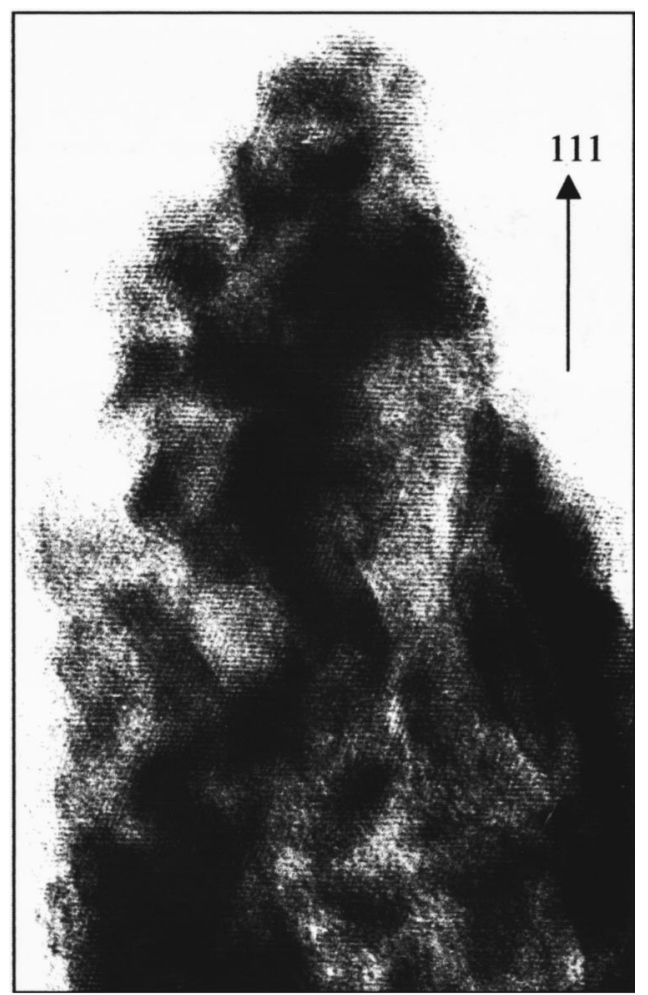

FIG. 5. High-resolution TEM image of magnetite formed at the beginning of the reduction process of sample $\mathrm{C} 2 \mathrm{~T}$ ( time $=0$ ).

direction of iron, as shown in Fig. 6. Hence, it appears that the orientation of the iron particles will depend on the orientation of the precursor. For example, iron particles obtained from goethite will preferentially have a [001] orientation, while iron particles obtained from hematite, as presented in this article will have a [111] orientation. In agreement with our data, different crystallographic orientations along the needle axis have been reported for iron particles such as [001], [111], or [110] without specifying the reason for the discrepancy. ${ }^{20,21}$

Finally, after 720 min of reduction, the particles show an electron-diffraction pattern that resembles to that of a single crystal of $\alpha-\mathrm{Fe}$ (Fig. 4). In this case, the crystallite size calculated from the $\mathrm{x}$-ray data $(30 \mathrm{~nm})$ is significantly smaller than the particle size observed by TEM (190

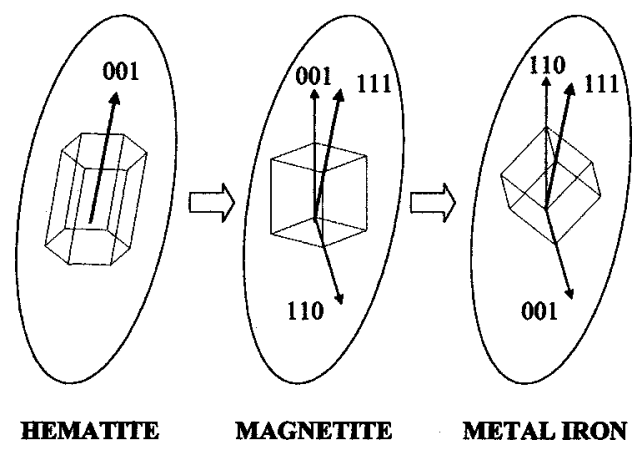

FIG. 6. Schematic representation of the topotactic transformation from hematite to metal iron observed by electron diffraction.

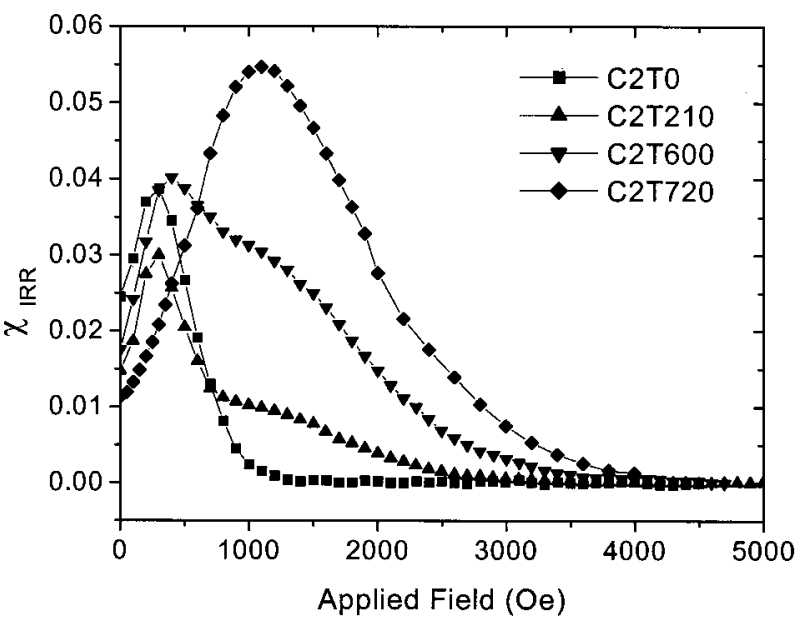

FIG. 7. Irreversible magnetic susceptibility as a function of the magnetic field $\left[\chi_{\text {irr }}(H)\right]$ at different times $(0,210,600$, and $720 \mathrm{~min})$ during the reduction process of sample $\mathrm{C} 2 \mathrm{~T}$.

$\times 40 \mathrm{~nm}$ ), suggesting that the final particles are composed of several crystals, all of which have the same orientation within the particle.

Also, an intermediate phase has been detected and identified as wustite $(\mathrm{FeO})$, in agreement with other work which postulated that the reduction of magnetite to iron goes via the intermediate wustite. ${ }^{22}$ Wustite appears after $30 \mathrm{~min}$ of reduction (XRD pattern not shown) and disappears just before the end of the reduction process (600 min) (Fig. 3).

The reduction process was also followed by irreversible magnetic susceptibility measurements $\left[\chi_{\text {irr }}(H)\right]$ (Fig. 7). Given the different magnetic behavior of $\mathrm{Fe}_{3} \mathrm{O}_{4}$ and $\alpha-\mathrm{Fe}$, the variation of $\chi_{\text {irr }}(H)$ as a function of the applied field for these two phases is expected to be dissimilar due to the lower contribution of the lower-shape anisotropy, and hence, coercivity of $\mathrm{Fe}_{3} \mathrm{O}_{4}$, and therefore the contribution to the total $\chi_{\text {irr }}(H)$ of both phases can be separated. The contribution of wustite to the susceptibility can be neglected due to the paramagnetic state of this oxide at room temperature. A progressive increase in the susceptibility due to $\alpha-\mathrm{Fe}$ is observed with an increase in the reduction time (Fig. 7). As observed, the total transformation to iron only takes place after prolonged heating $(720 \mathrm{~min})$. The irreversible susceptibility is very sensitive and it is able to distinguish the contributions from $\alpha-\mathrm{Fe}$ and magnetite. In fact, according to XRD (Fig. 3), $\alpha-\mathrm{Fe}$ is almost completely formed after $600 \mathrm{~min}$, however, the $\chi_{\text {irr }}$ curve clearly shows that a strong magnetite component still remains in the sample (Fig. 7). The complete reduction was also associated with an almost invariance of the $M_{S}$ value. The $M_{S}$ values do not reach a plateau value, because as will be mentioned below, the increase in Fe crystallite size with the reducing time.

A correlation was found between the magnetic parameters and the reduction time (Table I). As the reduction proceeds the $\alpha-\mathrm{Fe}$ content increases with respect to magnetite, which causes an increase in the $M_{S}$ value and coercivity at room temperature. However, it is important to mention that a certain contribution to the increase in $M_{S}$, specially at longer times where almost no magnetite is detected, could come 
TABLE I. Evolution of the iron crystallite size and hysteretic parameters with reduction time for sample $\mathrm{C} 2 \mathrm{~T}$, reduced at $450{ }^{\circ} \mathrm{C}$ under a hydrogen flow of $2 \mathrm{~L} / \mathrm{h}$.

\begin{tabular}{cccc}
\hline \hline & & \multicolumn{2}{c}{$\begin{array}{c}\text { Magnetic properties } \\
\text { at RT }\end{array}$} \\
\cline { 3 - 4 } $\begin{array}{c}\text { Reduction } \\
\text { time } \\
(\mathrm{min})\end{array}$ & $\begin{array}{c}\text { Crystallite } \\
\text { size }(\mathrm{XRD}) \\
(\mathrm{nm})\end{array}$ & $\begin{array}{c}M_{S} \\
\left(\mathrm{emu} \mathrm{g}^{-1}\right)\end{array}$ & $\begin{array}{c}H_{C} \\
(\mathrm{Oe})\end{array}$ \\
\hline 0 & 0 & 48 & 160 \\
90 & 20 & 51 & 180 \\
210 & 25 & 56 & 225 \\
600 & 28 & 105 & 555 \\
720 & 30 & 120 & 885 \\
\hline \hline
\end{tabular}

from the observed increase in the $\alpha$-Fe crystallite size with the reduction time (Table I). At the beginning and at the end of the reduction process, coercivity values are similar to those reported for ellipsoidal magnetite and iron particles, respectively. ${ }^{23}$ However, saturation magnetization values are slightly lower than those reported for magnetite and iron (80 and $220 \mathrm{emu} / \mathrm{g}$ ). ${ }^{23}$ These low values can be explained by the coexistence of several effects: First, the presence of alumina does not contribute to the magnetization. Second, considering the small particle size $(<200 \mathrm{~nm})$, spin canting at the surface and inside the particle can also be partially responsible for the observed decrease in saturation magnetization. ${ }^{24}$ Third, the presence of an iron oxide passivating layer on the particle surface does not contribute to the saturation magnetization and has been reported to be responsible for the reduction of the value of saturation magnetization. ${ }^{25}$

\section{B. Structural and magnetic characteristics of $\alpha-\mathrm{Fe}$ particles}

Pure metal particles were obtained by reduction of the alumina-coated hematite particles at different temperatures and under different hydrogen flow rates. For the hydrogen flow rates used in this work, temperatures higher than $400{ }^{\circ} \mathrm{C}$ were required to obtain pure iron particles. At lower temperatures, a mixture of metal iron and magnetite was always found. As expected, the necessary heating times (at $450{ }^{\circ} \mathrm{C}$ ) to achieve the full reduction of the particles were inversely proportional to the hydrogen flow rate. Thus, heating times between 4 and $12 \mathrm{~h}$ were needed to complete the reduction when the hydrogen flow rate was varied from 6 to $2 \mathrm{~L} / \mathrm{h}$ (samples C1T and C2T, respectively). At these flow rates, the particle size and shape were only slightly altered during the transformation, as observed in Fig. 8. Thus, metal particles obtained under these conditions (samples C1T and C2T) consisted of ellipsoidal particles of $\sim 190 \mathrm{~nm}$ in length and 40 $\mathrm{nm}$ in width, which means that there was a reduction in volume of around $15 \%$ during the transformation of the $\alpha-\mathrm{Fe}_{2} \mathrm{O}_{3}$ particles to $\alpha-\mathrm{Fe}$. A higher reduction in volume of around $60 \%$ would have been expected from the different density of these two phases, which is $\sim 5$ and $8 \mathrm{~g} / \mathrm{cm}^{3}$ for hematite and iron, respectively. In this case, the formation of pores inside the particles, clearly observed by TEM (Fig. 8), justify the small reduction in size. Significant changes in morphology and particle size were observed when using a

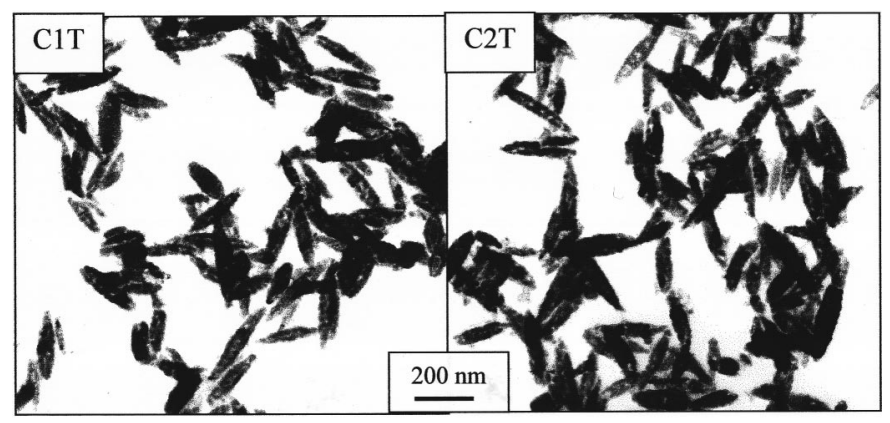

FIG. 8. Metal iron particles obtained at $450^{\circ} \mathrm{C}$ under different hydrogen flow rates (samples $\mathrm{C} 1 \mathrm{~T}$ and $\mathrm{C} 2 \mathrm{~T}$ ).

lower-hydrogen flow rate, $0.6 \mathrm{~L} / \mathrm{h}$ (sample C3T) and $0.2 \mathrm{~L} / \mathrm{h}$ (C4T). As a consequence of the longer annealing times for complete reduction (24 and 96 for sample C3T and C4T, respectively) some particles appeared broken and were sintered, showing round edges under the microscope (data not shown).

The kinetic of the reduction processes were followed by comparing the relative intensities of the x-ray diffraction peaks (110) of $\alpha-\mathrm{Fe}$ and (311) of $\mathrm{Fe}_{3} \mathrm{O}_{4}$ as a function of the reduction time (Fig. 9). It is clear that there is a continuous transformation for samples $\mathrm{C} 2 \mathrm{~T}$ and $\mathrm{C} 3 \mathrm{~T}$. However, in the case of sample $\mathrm{C} 1 \mathrm{~T}$, the transformation from magnetite to iron is almost complete after a reduction of $30 \mathrm{~min}$. This sharp increase in the intensity of the diffraction peaks for $\alpha-\mathrm{Fe}$ for sample C1T in the first stage of the reduction suggests a violent change in the structure. The crystallite size of the $\alpha-\mathrm{Fe}$ particles at the end of the reduction process was 22 $\mathrm{nm}$, significantly smaller that the crystallite size obtained under a lower-hydrogen flow rate (Table II). It seems that the number of $\alpha-\mathrm{Fe}$ crystallites inside the particle varies directly with the flow rate of hydrogen (i.e., with the annealing time) and therefore this experimental parameter determines the crystallite size of the final particles. Unfortunately, the hydrogen flow rate also determines the particle morphology, which can be significantly altered when the flow rate is so small that the heating time required to obtain pure metal iron is very long.

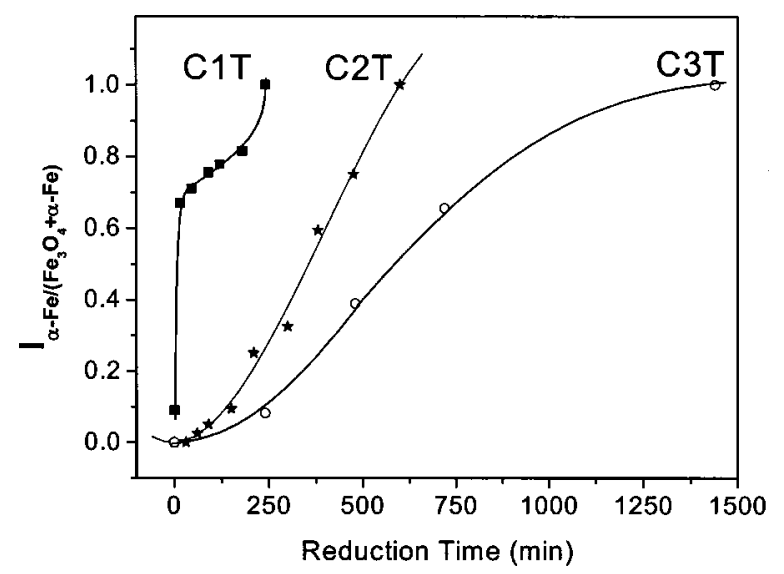

FIG. 9. Relative intensities of the x-ray diffraction peaks (110) of $\alpha$-Fe and (311) of $\mathrm{Fe}_{3} \mathrm{O}_{4}$ for samples $\mathrm{C} 1 \mathrm{~T}, \mathrm{C} 2 \mathrm{~T}$, and $\mathrm{C} 3 \mathrm{~T}$ as a function of the reduction time. 
TABLE II. Crystallite size and magnetic parameters of metal particles reduced at $450{ }^{\circ} \mathrm{C}$ under different hydrogen flow rates.

\begin{tabular}{lccccccc}
\hline \hline & \multicolumn{2}{c}{$\begin{array}{c}\text { Experimental } \\
\text { conditions }\end{array}$} & & & \multicolumn{4}{c}{$\begin{array}{c}\text { Magnetic properties } \\
\text { at RT }\end{array}$} \\
\cline { 2 - 3 } \cline { 6 - 8 } Sample & $\begin{array}{c}H_{2} \text { Flow } \\
(\mathrm{L} / \mathrm{h})\end{array}$ & $\begin{array}{c}\text { Time } \\
(\mathrm{h})\end{array}$ & $\begin{array}{c}\text { Crystallite } \\
\text { size }(\mathrm{XRD}) \\
(\mathrm{nm})\end{array}$ & $\begin{array}{c}M_{S} \\
\left(\mathrm{emu} \mathrm{g}^{-1}\right)\end{array}$ & $M_{R} / M_{S}$ & $\begin{array}{c}H_{C} \\
(\mathrm{Oe})\end{array}$ & $\begin{array}{c}V_{a} \\
\left(\mathrm{~nm}^{3}\right)\end{array}$ \\
\hline CIT & 6 & 4 & 22 & 115 & 0.36 & 885 & 12000 \\
C2T & 2 & 12 & 30 & 120 & 0.38 & 885 & 13000 \\
C3T & 0.6 & 24 & 45 & 132 & 0.23 & 625 & \\
C4T & 0.2 & 96 & 56 & 165 & 0.19 & 435 & 22000 \\
\hline \hline
\end{tabular}

The hysteretic parameters obtained from the magnetization curves of the metal particles reduced at $450{ }^{\circ} \mathrm{C}$ under different hydrogen flow rates are included in Table II. The saturation magnetization increases as the crystallite size increases due to the reduction in surface area, which means not only a lower proportion of an iron oxide passivation layer with respect to metal iron, but also a lower surface canting of the magnetic moments. In contrast, the squareness decreases as the crystallite increases from samples C1T and C2T to samples C3T and C4T, suggesting incoherent rotation of the magnetization for the final two samples. The lowest values of coercivity were obtained for sample C4T with the highest crystallite size $(56 \mathrm{~nm})$. However, the same coercivity (885 Oe) was obtained for samples $\mathrm{C} 1 \mathrm{~T}$ and $\mathrm{C} 2 \mathrm{~T}$ with different crystallite sizes. This result suggests that there are two factors affecting the coercivity in these samples. The first is the increase in the crystallite size from sample C1T to sample $\mathrm{C} 2 \mathrm{~T}$, which gives rise to an increase in the coercivity. The second is the slight modification of the morphology during the reduction, which is expected to be more pronounced for sample $\mathrm{C} 2 \mathrm{~T}$ than for sample $\mathrm{C} 1 \mathrm{~T}$ due to the longer heating time. It should be noted that in this material, the coercivity is almost entirely determined by the shape anisotropy of the iron core ${ }^{24}$ and therefore, the lost of acicularity gives rise to a decrease in the coercivity.

The effect of thermal activation on the switching process is more pronounced as the crystal size decreases. The activation volumes calculated from time-dependence measurements at fields around the coercivity are given in Table II. The activation volume of reversal for all the samples are smaller than the physical volume of the particles, as determined from TEM pictures, by a factor of about ten and increases with the crystallite size (Table II). This value of the activation volume corresponds to a coherent reversal volume of diameter around $23 \mathrm{~nm}$ for samples $\mathrm{C} 1 \mathrm{~T}$ and $\mathrm{C} 2 \mathrm{~T}$, which agrees well with the crystallite size calculated from $\mathrm{x}$-ray diffraction. For sample C4T, the corresponding dimension is $28 \mathrm{~nm}$, which is half the calculated crystallite size, supporting our view of incoherent rotation of the magnetization in this sample.

\section{CONCLUSIONS}

It was found that the use of monodispersed alumina coated $\alpha-\mathrm{Fe}_{2} \mathrm{O}_{3}$ microellipsoidal particles is specially adequate to study both the transformation of iron oxide into $\alpha-\mathrm{Fe}$ and to determine the influence of processing condi- tions on the magnetic behavior of the final metal particles. It was found that the transformation of $\alpha-\mathrm{Fe}_{2} \mathrm{O}_{3}$ into $\alpha-\mathrm{Fe}$ proceeds in three stages with magnetite and wustite as reaction intermediates. Selective area electron-diffraction patterns showed that the transformation is topotactic with the orientation of the final iron particles depending on the orientation of the precursor. Finally, it can be concluded that in order to obtain a sample with high magnetization and high coercivity, the hydrogen flow rate used in the reduction should be optimized. It should be low to produce the minimum number of iron nuclei within the magnetite particle but high enough to avoid the growth of the iron nuclei above the critical single domain size.

\section{ACKNOWLEDGMENTS}

This work was supported by the CICYT under Project No. PB98-0525. Also, Dr. M.P. Morales, L.C. Varanda, and P. Tartaj gratefully acknowledge the Domingo Martinez Foundation, the Brazilian agency FAPESP, and the Royal Society, respectively, for financial support.

${ }^{1}$ M. P. Sharrock, IEEE Trans. Magn. 36, 2420 (2000).

${ }^{2}$ K. O'Grady and H. Laidler, J. Magn. Magn. Mater. 200, 616 (1999).

${ }^{3}$ S. Hisano and K. Saito, J. Magn. Magn. Mater. 190, 371 (1998).

${ }^{4}$ S. Onodera, H. Kondo, and T. Kawana, MRS Bull. 21, 28 (1996).

${ }^{5}$ N. Sugita, M. Mackawa, Y. Ohta, K. Okinaka, and N. Nagai, IEEE Trans. Magn. 31, 2854 (1995).

${ }^{6}$ M. Kishimoto, T. Nakazumi, N. Otani, and T. Sueyoshi, IEEE Trans. Magn. 27, 4645 (1991).

${ }^{7}$ R. J. Veitch, A. Ilmer, W. Lenz, and V. J. Richter, J. Magn. Magn. Mater. 193, 279 (1999)

${ }^{8}$ M. P. Morales, S. A. Walton, L. S. Prichard, C. J. Serna, D. P. E. Dickson, and K. O'Grady, J. Magn. Magn. Mater. 190, 357 (1998).

${ }^{9}$ M. P. Morales, C. J. Serna, K. O’Grady, L. S. Prichard, J. A. Hutching, G. H. Milford, and D. P. E. Dickson, J. Magn. Magn. Mater. 193, 314 (1999).

${ }^{10}$ A. A. Van der Giessen and C. J. Klomp, IEEE Trans. Magn. 5, 317 (1969).

${ }^{11}$ E. Matijevic, Chem. Mater. 5, 412 (1993).

${ }^{12}$ M. Ozaki, S. Kratohvil, and E. Matijevic, J. Colloid Interface Sci. 102, 146 (1984).

${ }^{13}$ S. Hisano, K. Saito, S. Aizawa, K. Sano, K. Matsumoto, and K. Murata, US Patent No. 5591535, (1997).

${ }^{14}$ G. Parks, Chem. Rev. 39, 177 (1965).

${ }^{15}$ L. V. Azároff, Elements of X-ray Crystallography (McGraw-Hill, New York, 1968) p. 549.

${ }^{16}$ A. M. de Witte, K. O'Grady, G. N. Coverdale, and R. W. Chantrell, J. Magn. Magn. Mater. 88, 183 (1990).

${ }^{17}$ P. Gaunt, J. Appl. Phys. 59, 4129 (1986).

${ }^{18}$ M. P. Morales, C. Pecharromán, T. González-Carreño, and C. J. Serna, J. Solid State Chem. 108, 158 (1994).

${ }^{19}$ R. M. Cornell and U. Schwertmann, The Iron Oxides. Structure, Properties, Reactions, Occurrence and Uses (VCH, Weinheim, 1996).

${ }^{20}$ F. E. Luborsky, E. F. Koch, and C. R. Morelock, J. Appl. Phys. 34, 2905 (1963). 
${ }^{21}$ R. J. Veitch, H. J. Richter, P. Poganiuch, H. Jakusch, and E. Schwab, IEEE Trans. Magn. 30, 4074 (1994).

${ }^{22}$ A. V. Bradshaw, London: Institution of Mining and Metallurgy, C281C294 (1970)

${ }^{23}$ G. Bates, Ferromagnetic Materials, edited by E. P. Wohlfarth
(North-Holland, Amsterdam 1980) p. 442.

${ }^{24}$ M. P. Morales, C. J. Serna, F. Bødker, and S. Mørup, J. Phys.: Condens. Matter 9, 5461 (1997).

${ }^{25}$ F. T. Parker, F. E. Spada, T. J. Cox, and A. E. Berkowitz, J. Appl. Phys. 77, 5853 (1995). 